\title{
O ROMANTISMO BRASILEIRO EM FOCO: ANÁLISE DAS REPRESENTAÇÕES DE EDUCAÇÃO LITERÁRIA NO MANUAL DIDÁTICO "PORTUGUÊS CONTEMPORÂNEO: DIÁLOGO, REFLEXÃO E USO"
}

\author{
BRAZILIAN ROMANTICISM IN FOCUS: ANALYSIS OF THE \\ REPRESENTATIONS OF LITERARY EDUCATION IN THE PORTUGUESE \\ TEACHING MANUAL CONTEMPORARY: DIALOGUE, REFLECTION AND USE
}

\author{
Jaine Neves Pires ${ }^{1}$ \\ Oton Magno Santana dos Santos ${ }^{2}$
}

\begin{abstract}
Resumo: O presente trabalho se constitui como uma pesquisa bibliográfica a fim de investigar como os conteúdos das representações presente no manual didático Português Contemporâneo: diálogo, reflexão e uso, da segunda série do ensino médio sugerem formas de apropriação da temática "Romantismo brasileiro", a partir de modelos de educação literária indicados aos professores e aos estudantes de uma escola pública estadual do ensino médio de Brumado (BA). Dessa feita, iniciamos o processo de análise com base em conceitos de educação literária, livro didático e escolarização da literatura, proposto por autores como Roxane Rojo, Maria José Coracini, Rildo Cosson, Célia Cassiano e Cyana Lahy-Dios, entre outros. A partir da História cultural de Roger Chartier, sustentamos o referencial teórico deste artigo com os conceitos de representação e apropriação. A coleta de dados compreenderá a análise e interpretação dos dados encontrados na investigação.
\end{abstract}

Palavras-chave: Literatura; livro didático; representação; apropriação.

\begin{abstract}
The present work is constituted as a bibliographical research in order to investigate how the contents of the representations present in the Contemporary Portuguese didactic manual: dialogue, reflection and use, from the second grade of high school suggest ways of appropriation of the theme "Brazilian Romanticism", from of models of literary education indicated to teachers and students of a state public high school in Brumado (BA). This time, we started the process of analysis based on concepts of literary education, textbook and schooling of literature, proposed by authors such as Roxane Rojo, Maria Jose Coracini, Rildo Cosson, Celia Cassiano and Cyana Lahy-Dios, among others. From Roger Chartier's cultural history, we support the theoretical framework of this article with the concepts of representation and appropriation. The data collection will comprise the analysis and interpretation of the data found in the investigation.
\end{abstract}

Keywords: Literature; textbook; representation; appropriation.

A escola se constitui como um dos meios mais importantes de contato com a literatura, principalmente pela legitimidade que reivindica ao lidar com esse tipo de arte. Isso se dá porque muitos dos estudantes não têm a familiaridade com a leitura literária em casa, diante de fatores sociais como o econômico e o cultural. Vale ressaltar que é comum aos alunos lerem outros tipos de literatura, como os best sellers, fanfic, dentre outros que não são apresentados na escola, ou seja, eles ignoram que as leituras que realizam também são literaturas. Assim, os questionamentos de como a literatura é trabalhada em sala de aula vem à tona, uma vez que os conteúdos abordados no livro didático são enquadrados:

\footnotetext{
${ }^{1}$ Universidade do Estado da Bahia.

${ }^{2}$ Universidade do Estado da Bahia.
} 
[...] No campo das produções sobre literatura, estudos de obras clássicas e de estilos de época, centradas e classificações, abordagens estruturais, provas e fichas de "livro", atividades com objetivos estritamente informativos e formativos; no campo de produções de literatura, adaptações redutoras, simplificações de obras, coleções com narrativas segundo fórmulas que mercadologicamente funcionam, com banalizações de linguagem e de temática, em detrimento da experiência estética ou ética do leitor com o próprio bem simbólico, em sua origem ou em sua essência literária (EVANGELISTA; BRANDÃO \& MACHADO, 2006, p. 13).

Nesse sentido, o tratamento dado à literatura pelo livro didático estabelece modelos de leitura a partir de fragmentos interpretados isoladamente e da historiografia que limita a literatura apenas a escolas literárias, tornando-a pretexto para avaliações ao invés de contribuir para a formação cultural do cidadão. A manutenção desse sistema de ensino tem como consequência um ensino repetidor que prioriza o aspecto decorativo do texto e expressa o ideário dominante da sociedade capitalista. Assim, há a transmissão de valores, crenças e concepções de mundo que pertencem ao sistema ao qual se inserem os autores, editores, compradores e demais integrantes e que, consequentemente, encontram-se presentes em sua realidade social. Nesse caso, a formação literária dos que frequentam a escola está calcada em abordagens meramente informativas sobre cânone, história e características literárias de obras e escolas. Todas essas concepções encontram-se ainda mais frequentes no ensino médio, como nos afirma Cosson (2009):

No ensino médio, o ensino da literatura limita-se à literatura brasileira, ou melhor, à história da literatura brasileira, usualmente na sua forma mais indigente, quase como apenas uma cronologia literária, em uma sucessão dicotômica entre estilos de época, cânone e dados biográficos dos autores, acompanhada de rasgos teóricos sobre gêneros, formas fixas e alguma coisa de retórica em uma perspectiva para lá de tradicional. Os textos literários, quando comparecem, são fragmentos e servem prioritariamente para comprovar as características dos períodos literários antes [...] (COSSON, 2009, p. 21).

O livro didático é a fonte mais utilizada no ensino por razões que vão desde o acesso viabilizado pelo MEC, quanto pela praticidade em seu papel de integrante do processo de ensino-aprendizagem nas escolas. Especificamente, o livro didático de português proporciona o envolvimento do estudante com o mundo da escrita e da literatura, na maioria das vezes, delineando o trabalho do professor. Essa visão conscientemente limitada pelos responsáveis pela criação do livro didático acaba levando o leitor a internalizar um fato como verdade absoluta, sem proporcionar questionamentos do que está posto.

É importante frisarmos que o livro didático nasceu dos anseios de setores influenciadores da sociedade brasileira em legitimar o ensino, à luz de suas ideologias. Sob essa perspectiva, o LD procura atender e propagar os discursos simbólicos dessas parcelas privilegiadas da cultura nacional. Além disso, configura-se como instrumento político, a partir da adequação às leis educacionais do governo que, de posse de seus discursos legalizadores, determina e qualifica os manuais mediante critérios que atendam às suas demandas. $\mathrm{O}$ que ocorre, a partir de uma poderosa força de representação consolidada em acordos entre sociedade e política, é a consequente legitimação desses discursos nas escolas, proferidos pelos seus agentes, principalmente os professores, e assimilados pelos alunos como verdades incontestáveis. Nesse sentido, Coracini, (1999) observa que: 
Para os professores "fiéis", o livro didático funciona como uma bíblia, palavra inquestionável, monumento, como lembra Souza (1995), analisando o livro didático como Foucault analisa o documento histórico: a verdade aí está contida; o saber sobre a língua e sobre o assunto a ser aprendido ali se encontra. Desse modo, as perguntas, sempre "bem" formuladas, evidentemente, só podem ser respondidas de acordo com o livro do professor, de tal maneira que o professor raramente se dá conta quando uma pergunta não foi bem formulada, dificultando a obtenção da resposta "certa", determinada pelo autor do LD; este autoridade reconhecida carregaria, então, a aura da verdade, da neutralidade, do saber (CORACINI, 1999, p. 23).

Como principal suporte do trabalho docente nas escolas públicas brasileiras, o livro didático é, ainda hoje, a principal ferramenta utilizada por professores e alunos. No entanto, esse manual é pensado para o professor, já que, muitas vezes, é ele quem escolhe o compêndio a ser utilizado durante o ano letivo, diante dos modelos limitados apresentados pela instituição e pelas editoras. Sendo assim, há docentes que utilizam o livro didático como uma única fonte de pesquisa, como verdade absoluta: "[...] tal como se apresenta hoje, [...] tem sido o instrumento de letramento mais presente na escola brasileira, especialmente a partir da década de 1970 [...]" (JURADO; ROJO, 2016, p. 44).

A centralidade que confere autoridade ao livro didático na educação, repleto de saberes prontos, não deve ser apresentado como única fonte para direcionar o processo de ensinoaprendizagem. O LD é um instrumento de apoio ao trabalho pedagógico e não uma sabedoria suprema. Além disso, seleciona os cânones literários, contribuindo para uma consequente consolidação dos referidos cânones. Porém, a forma como indica o processo de ensinoaprendizagem de conteúdos da literatura canônica é equivocada:

[...] quando apresentamos uma obra literária aos nossos alunos, comumente, a preocupação não é com a fruição ou a apreciação estética. Ela se torna um objeto para o ensino das características presentes na obra, ligadas à escola literária ou às figuras de linguagem que possam ter sido usadas pelo autor. Fragmentamos a obra, não poucas vezes, reduzindo-a a um conjunto de características de uma escola literária ou de um estilo próprio do autor (JURADO; ROJO, 2006, p. 46).

A prática da leitura desenvolvida com apoio do livro didático, mais especificamente o livro didático de português, produz envolvimento do estudante com o mundo da escrita e da literatura; contudo, a cultura escolar, apesar de investir pedagogicamente na leitura, ainda camufla a leitura literária no que ela tem de próprio. A leitura, com vistas ao letramento literário, torna-se indissociável do livro didático de português; afinal, esse compêndio ainda é o principal material de acesso que os estudantes têm para as práticas de escrita e leitura. Nesse material, ainda há uma limitação de textos que são considerados complexos de entendimento, quando não os fragmentam ou sintetizam, tornando-os descontextualizados e afetando sua coesão. A parte de literatura que está englobada no LD de português é descrita por fragmentos de narrativas e poemas que são sugeridos para o ensino de gramática e ortografia, distorcendo as características da poesia e dando uma função reducionista para a literatura. Essas práticas, frequentemente presentes no sistema de ensino brasileiro, mostram a inadequada escolarização da literatura que atribui uma função imediata ao texto literário sem se preocupar com a sua especificidade. Desse modo,

[...] O que se pode criticar, o que se deve negar não é a escolarização da literatura, mas a inadequada, a errônea, a imprópria escolarização da literatura que se traduz 
em sua deturpação, falsificação, distorção, como resultado de uma pedagogização ou uma didatização mal compreendidas que, ao transformar o literário em escolar, desfigura-o, desvirtua-o, falseia-o [...]. (SOARES, 2006, p. 22).

De acordo com Soares (2006), as lacunas existentes no ensino de literatura brasileira verificam-se na didatização dos textos literários, em uma escolarização da leitura literária errônea, pautado na transmissão do conhecimento em detrimento da própria leitura da obra a ser estudada, visto que a cultura escolar preocupa-se em seguir o que é imposto de cima para baixo, no qual os modelos instituídos de educação literária se consolidam nas práticas pedagógicas privilegiando autores, textos e formas de apropriação da literatura:

Partindo do pressuposto de que um dos principais papéis da educação literária como disciplina de estudos é a representação cultural de sociedades, é preciso observar que ele se submete a imposições verticais, tais como programas e requisitos de avaliação. Uma análise de sua realização como parte do processo educativo requer a observação das ações pedagógicas em salas de aula de literatura. Requer, também, que se ouça o que alunos e professores têm a dizer, sendo importante que a literatura integre o domínio de outras disciplinas de cunho social, visando à produção de conhecimento relevante para indivíduos e grupos sociais (LEAHY-DIOS, 2004, p. 10).

Cyana Leahy-Dios, nos provoca acerca do caráter puramente didático da literatura e nos faz repensar essas práticas ao defender que a literatura seja tratada de forma consciente pelos alunos e pelos os professores. Concomitantemente, o modelo de educação literária esperado é aquele que suscite discussões e reflexões a partir do que está sendo trabalhado, não se resumindo apenas aos preceitos do livro didático. Destarte, o âmbito escolar deve formar, orientar e oferecer possibilidades aos alunos para o desenvolvimento da leitura literária, provocando sua criticidade e assim, criar condições para defender o seu ponto de vista. "Por fim, devemos compreender que o letramento literário é uma prática social e, como tal, responsabilidade da escola [...]." (COSSON, 2019, p. 23).

Ao se conscientizar de que a literatura é um produto social, a prática da leitura se concretiza em letramento literário, como uma atividade significativa para os alunos. Portanto, não basta somente ler fragmentos de textos, resumos de obras, é preciso inserir o estudante em um mundo literário. Tornar o ensino-aprendizagem de literatura em uma prática significativa deve ser prioridade na escola, sendo dessa instituição, talvez a grande responsabilidade de formar alunos leitores. Para tanto, faz-se necessário repensar o conceito de literatura, seu valor e função social.

Buscamos na História Cultural o suporte necessário ao desenvolvimento desta pesquisa, a fim de compreender os modelos de educação literária legitimados no sistema de ensino brasileiro, sendo-a definida por Roger Chartier (1988):

A história cultural, tal como a entendemos, tem por principal objetivo identificar o modo como em diferentes lugares e momentos uma determinada realidade social é construída, pensada, dada a ler. Uma tarefa deste tipo supõe vários caminhos. O primeiro diz respeito às classificações, divisões e delimitações que organizam a apreensão do mundo social como categorias fundamentais de percepção e de apreciação do real. Variáveis consoante as classes sociais ou os meios intelectuais são produzidas pelas disposições estáveis e partilhadas, próprias do grupo. São esses esquemas intelectuais incorporados que criam as figuras graças às quais o presente pode adquirir sentido, o outro tornar-se inteligível e o espaço ser decifrado (CHARTIER, 1988, p. 22). 
O livro didático é um objeto que se constitui a partir de práticas representativas, como o econômico e o cultural destinadas a moldar certos padrões concebidos por um grupo dominante. Desta forma, várias representações são construídas e compartilhadas, e as imagens dessas representações são analisadas e interpretadas de diversas formas. Os modelos de educação literária presentes nestes manuais sugerem formas de apropriação e representação da posição e interesse de quem ocupa determinado espaço em que, [...] embora aspirem à universalidade de um diagnóstico fundado na razão, são sempre determinadas pelos interesses de grupo que as forjam. Daí, para cada caso, o necessário relacionamento dos discursos proferidos com a posição de quem os utiliza (CHARTIER, 1988, p. 17).

Em outras palavras, os discursos legitimadores do livro didático representam as imposições e resistências políticas, claramente atravessadas pela noção de "poder", segundo as quais o autor manipula o leitor, através da representação que ele tem, impedindo-o de reconhecer as relações das produções culturais. A educação literária, desse modo, é formulada por uma realidade social extraída de um dado momento e propagada como verdades incontestáveis. Assim, esse sistema de ensino de literatura se apoia nas indicações de como se ensinar os conteúdos em um ensino pautado na memorização de períodos, datas, nomes de autores e de obras e principais características de obras e períodos. São, portanto, indicações de como o estudante deve se apropriar do conteúdo ensinado:

A apropriação, tal como a entendemos, tem por objectivo uma história social das interpretações, remetidas para as suas determinações fundamentais (que são sociais, institucionais, culturais) e inscritas nas práticas específicas que as produzem. Conceder deste modo atenção às condições e aos processos, que muito concretamente, determinam as operações de construção do sentido (na relação de leitura, mas em muitas outras também) é reconhecer, contra a antiga história intelectual, que as inteligências não são desencarnadas, e, contra as correntes de pensamento que postulam o universal, que as categorias aparentemente mais invariáveis devem ser construídas na descontinuidade das trajectórias históricas (CHARTIER, 1988, p. 27).

De acordo com Chartier, o conceito de apropriação contempla a liberdade de que dispõe o leitor para se apropriar de informações a partir dos diversos contextos em que se encontram. No entanto, no âmbito escolar, a apropriação da literatura encontra-se configurada amplamente pelo livro didático, o que não possibilita uma criticidade dos alunos, ao postular uma verdade única. Assim, os conteúdos de literatura determinam modelos de apropriação tanto por parte dos professores quanto por parte dos alunos a partir das indicações presentes no livro didático instituído por grupos políticos e sociais dominantes.

Para ilustrar nossas observações, analisamos os conteúdos do Romantismo brasileiro presente no manual didático Português contemporâneo: diálogo, reflexão e uso, por ser uma temática que marca o início da periodização literária no Brasil.

Apresentamos na sequência, o método historiográfico e descritivo de como a literatura é trabalhada no livro didático, a partir de uma passagem que representa a limitação da literatura através da historiografia:

Nesta unidade, você vai estudar a prosa romântica, que teve no romance a sua maior expressão. $\mathrm{O}$ grande desenvolvimento que esse gênero experimentou no século XIX tem relação, principalmente, com as transformações sociais ocorridas após as revoluções burguesa e industrial na Europa. O retrato de uma sociedade em contínuo processo de mudança era um desafio para os 
gêneros literários clássicos (a epopeia, a tragédia e a lírica), enquanto o romance, um gênero mais flexível quanto a temas e a aspectos formais, tinha maior possibilidade de corresponder aos novos anseios de representação dessa época. Além disso, a produção literária na Europa já não era mais financiada por reis, príncipes e aristocratas, e sim por livreiros, que pretendiam conquistar um público leitor crescente, formado sobretudo pela classe burguesa. A necessidade de os romances serem acessíveis a um público leitor menos instruído acabou contribuindo para o desenvolvimento de determinadas inovações técnicas, no gênero, como descrições abundantes, explicações ao longo do texto e linguagem mais clara e direta.

No Brasil, após a chegada da família real e a proclamação da Independência, o contato com a Europa ampliou-se significativamente, de maneira que a moda, as artes, a literatura e os costumes europeus, sobretudo franceses, tornaram-se nossas principais referências culturais. Esse foi o contexto que levou à difusão, no Brasil, na primeira metade do século XIX, de romances europeus, em língua original ou traduzidos. Como consequência do grande sucesso desses romances, escritores nacionais iniciaram a produção do gênero no país e, orientados pela concepção romântica de valorizar a cultura, as raízes e as tradições nacionais, produziram romances que podem se classificados como indianistas, históricos, regionais e urbanos. José de Alencar, pela extensão e pela qualidade de sua obra, é considerado o principal romancista do Romantismo brasileiro (CEREJA; VIANA; DAMIEN, 2016, p. 100-101).

Portanto, no livro didático, a literatura serve como história para explicar o passado, descaracterizando-a do seu não compromisso com o real, de forma a contribuir para a imposição de uma verdade literária baseada em contexto histórico e biografia de escritores que privilegiam formas de representação imposta aos alunos e aos professores. Assim, a tendência é que a escola, por meio do LD, reproduza um ensino pautado em métodos que se preocupam em apresentar aos alunos a periodização literária, os autores canônicos que se destacam no manual, o que escreveram e a qual escola pertencem, contribuindo assim para a inadequada escolarização da literatura.

As atividades didáticas propostas, expressam valores e visões de mundo acerca dos movimentos literários, instituindo modelos de apropriação de leitura em uma formação leitora que, ao invés de ler literatura e ampliar o horizonte dos alunos recai em uma prática que trabalham os gêneros apresentados pelos livros didáticos de forma tradicional, seja pelo fato de ser cômodo para conduzir a aula, ou pela falta de incentivo aos professores de buscar novas iniciativas dinâmicas para desenvolver suas aulas. Dessa forma, o manual didático aborda atividades que não instigam a imaginação e a criticidade dos alunos, o que nega a esses sujeitos o direito de se apropriar do texto literário de outras formas que não aquela consagrada e canonizada pelo livro didático.

Outro aspecto a ser analisado é o modo como os conteúdos de literatura são apresentados de forma sintetizada, em uma metodologia que visa explorar os recursos sintáticos e semânticos do texto literário, de maneira que os limita. Ao invés de propor as atividades como forma de ampliar os níveis de compreensão da leitura, tem se uma prática que desfigura o texto literário, como um trecho do navio negreiro, um dos poemas da obra Os escravos do escritor Castro Alves que é abordado no livro didático como subterfúgio para se trabalhar apóstrofes:

1. O eu lírico de um poema pode-se dirigir a alguém ou a algo que esteja presente ou ausente, que seja animado, ou inanimado, concreto ou abstrato, para exprimir lamentos, pedidos, censuras. Esse recurso retórico é uma figura de linguagem, chamada apóstrofe. 
a. Identifique as apóstrofes empregadas nas duas primeiras estrofes do poema.

b. Nessas duas estrofes, que pedidos o eu lírico faz aos seus interlocutores?

c. Que efeito o emprego das apóstrofes produz no texto?

2. A partir da terceira estrofe, há uma mudança na voz do poema.

a. De quem é essa voz?

b. Que informações essa nova voz introduz no poema? Justifique sua resposta com elementos do texto. (CEREJA; VIANA; DAMIEN, 2016, p. 71).

Percebemos que uma obra literária não pode ser usada para cumprir atividades mecanicistas, como responder questionários associados ao ensino de gramática, sem instigar no aluno a prática da leitura. $\mathrm{O}$ manual falha ao trazer trechos e citações de obras, das quais os alunos jamais tiveram acesso, em uma prática que não basta dizer que existiram obras no século XVIII, dizer suas temáticas e depois cobrá-las em avaliações. Temos que oportunizar aos educandos, ler, debater, degustar obras literárias com o prazer pela leitura e não com a obrigação de decorar. Pela orientação do LD, a decifração é sempre voltada para consagrar práticas que deturpam o texto em função do código normativo.

A leitura de textos literários ainda tem sido usada como pretexto para atividades estritamente estruturais de trabalho com a língua. O livro didático citado nessa pesquisa fragmenta poemas com o intuito de ensinar gramática utilizando frases soltas para explicar o assunto, sem explorar o texto, em uma atividade mecânica que limita a aprendizagem, visto que essa prática de ensino tradicional há muito tempo se mostra ineficaz, sem uma apreensão necessária entre o conteúdo e a forma poética construída. Veremos a seguir a descrição do conteúdo de uma página do LD que demonstra isso:

No estudo de literatura deste capítulo, você leu o poema "Meu anjo", de Álvares de Azevedo. Releia estes versos do poema:

"Meu anjo tem o encanto, a maravilha

Da espontânea canção dos passarinhos;

Tem os seios tão alvos, tão macios

Como o pelo sedoso dos arminhos.

[...]

É leve a criatura vaporosa

Como a frouxa fumaça de um charuto."

Observe que o eu lírico, ao descrever a mulher amada, procura ressaltar sua delicadeza e seu aspecto angelical. Para isso, associa-a a elementos delicados e fluidos, como a "espontânea canção dos passarinhos", "o pelo sedoso dos arminhos" e a "frouxa fumaça de um charuto". Procura destacar também atributos físicos dela, como a beleza dos seios, em "tão alvos, tão macios".

Note que, para caracterizar a mulher amada, o eu lírico emprega palavras como espontânea (canção), alvos e macios (seios), sedoso (pelo), vaporosa (criatura) e frouxa (fumaça). Essas palavras são adjetivos e seu emprego é essencial quando se quer descrever um substantivo ou atribuir a ele um juízo de valor.

Do ponto de vista semântico, os adjetivos podem ser conceituados assim:

Adjetivos são palavras que caracterizam, delimitam e qualificam o substantivo. Do ponto de vista morfológico, os adjetivos, assim como os substantivos, podem ser conceituados como palavras que apresentam gênero (masculino e feminino) e número (singular e plural) e concordam sempre com o substantivo a que se referem. 
Às vezes, o adjetivo não é formado por uma única palavra, mas por uma expressão. É o caso, por exemplo, de "canção de passarinho" em que a expressão de passarinho especifica canção. Nesse caso, chamamos a expressão de passarinho de locução adjetiva. Há locuções adjetivas também em: clara em neve, doce de leite, xícara de porcelana, pessoas de bem, etc. (CEREJA; VIANA; DAMIEN, 2016, p. 55).

É visto que o modo pelo qual o texto literário é apresentado no $L D$, atribui-lhe uma função imediata, que objetiva o ensino da gramática normativa, ignorando as suas especificidades. Desse modo, retira-o de seu contexto e o utiliza como justificativa às questões de análise linguística que de forma descontextualizada, transforma o texto literário em mero texto didático, dissociando-o de sua qualidade artística. Soma-se a isso a proposta engessada dos estudos literários que pouco contribui para a formação de um leitor crítico.

Percebemos que o manual didático apresenta sempre os mesmos métodos: a cada início de capítulo sobre literatura traz uma imagem, o contexto histórico em que o período a ser trabalhado está inserido, se assemelhando mais a uma aula de história, a biografia do autor, fragmentos de textos literários de escritores que sempre se fazem presentes e por último, questões de interpretação de textos. Essas práticas educacionais legitimam um discurso que impõe o que tem de ser dito e como deve ser dito, sequencialmente, em um modelo de educação literária concebido por instituições políticas dominantes.

A maneira como a literatura é conduzida não exige do aluno um pensamento crítico, nem ao menos amplia seu horizonte de leituras, mas somente a decodificação do código escrito. A exposição verbal da matéria, exercícios que não passam da memorização e/ou fixação do conteúdo, fazem com que os alunos percam o interesse pelo aprendizado. Ao converter o texto literário em instrumento pedagógico, o sistema educacional brasileiro nega o direito àquele sujeito de se apropriar do texto literário de outras formas que não aquela consagrada e canonizada pelas escolas. A transmissão dos conteúdos é pautada no método expositivo na difusão do conhecimento em detrimento da própria leitura da obra a ser estudada.

O que observamos do livro didático em análise, é que ele subentende um aluno leitor familiarizado com os textos que são propostos, já que estes só são apresentados a partir de fragmentos e resumos não levando em consideração o conhecimento prévio dos alunos, em uma prática que os distancia do texto. Assim, o favorecimento de um ensino elitizado é perceptível diante dos conteúdos apresentados que exigem um aluno que tenha tido o contato com as obras literárias, não se atentando para a realidade de muitos brasileiros que só tem o contato com a literatura na escola, posto que o fator econômico não permita gozar da compra de livros para o deleite da leitura em casa.

Vale ressaltar que há, ao longo da obra, um diálogo entre os textos literários do período em estudo e textos recentes de diferentes gêneros, tais como o cordel e a letra de canção. Além dos textos verbais, há, da mesma maneira, propostas de diálogos entre textos multimodais como o filme e história em quadrinhos. Esse trabalho com diferentes linguagens amplia o universo cultural do estudante em uma análise do texto e seu contexto como processo auxiliador na aprendizagem. Dessa forma, cabe ao professor utilizar essas linguagens como um caminho possível para o desenvolvimento do leitor literário, transformando a aula em uma oportunidade para o enriquecimento cultural.

Nas orientações didáticas, percebemos que os autores do LD analisado dizem fundamentarse em concepções teóricas como a de Antonio Candido, Regina Zilberman, dentre outros, tomando a abordagem desses autores para afirmar o modelo de ensino de literatura presente no manual. Mas, ao falar sobre o direito à literatura, Candido vai de encontro a este modelo perpetuado pelo LD, pois concebe a literatura como um dos direitos humanos. $\mathrm{O}$ autor defende que a literatura seja entendida como um "bem incompressível", ou seja, aquilo que não se pode negar a ninguém, como alimento, 
casa e roupa, por exemplo. Logo, questionamos a incoerência existente sobre aquilo que é perpetuado pelo $\mathrm{LD}$ e o que realmente dizem os teóricos da literatura brasileira.

No que diz respeito às atividades propostas sobre a temática "Romantismo brasileiro", os autores consideram o nacionalismo um traço essencial e, desse modo, abordam escritores importantes do cânone como José de Alencar e Gonçalves Dias, em uma proposta de valorização do caráter nacional. Além disso, o LD aponta as três gerações românticas, destacando as características de cada uma delas e seus autores principais, que se constituem como possibilidades de representação do nacionalismo literário.

Por fim, notamos a presença de imagens em todos os capítulos que iniciavam o assunto "Romantismo brasileiro" sugerindo uma relação entre a imagem e a proposta do capítulo, com uma legenda ampliada que comenta a obra. Além dessa imagem, em destaque, há também textos e imagens relacionados aos conteúdos de gramática e de literatura. Essas gravuras auxiliam na compreensão do leitor às informações apresentadas no capítulo como possibilidades de dialogar com o que está sendo estudado.

\section{Considerações finais}

De acordo ao que foi investigado, a manutenção de dogmas pelo LD revela uma homogeneização da literatura que prioriza o aspecto memorizável do texto ao invés de provocar a criticidade do leitor a partir de leituras literárias. Essa prática vai de encontro ao que Chartier aborda na história cultural, a qual concebe o ato de ler como um processo de interação texto/leitor. Por sua vez, os textos selecionados para trabalhar a temática "Romantismo brasileiro", apresentam uma concepção de leitura literária que não vai além de posturas previsíveis e permitidas por um modelo instituído de educação literária.

Entendemos, portanto, a necessidade de uma educação estética do sujeito que se pretende formar professor/leitor de literatura, já que ele é vítima de um ensino que reproduz a inadequada escolarização da literatura, conforme o modo como o conteúdo de literatura é apresentado no LD aos seus leitores/usuários. Esses manuais didáticos representam um discurso legitimado na/da escola, que mesmo sendo um suporte para o docente, atua como o único método utilizado, seja pela falta de formação, seja pela precariedade das escolas brasileiras que não oferecem outros suportes para a efetivação do ensino.

Pelo o exposto, concluímos que o livro didático Português contemporâneo: diálogo, reflexão e uso, contribui para a transmissão de conteúdos, sem se preocupar como as especificidades do seu público alvo, exigindo leitores familiarizados com as obras literárias, já que estas só são apresentadas por meio de resumos, fragmentos isolados e da historiografia, deixando claro o distanciamento em exercer o gosto pela leitura, sem conscientizá-los de seus lugares sociais, impossibilitando-os de se tornarem leitores críticos.

Por fim, consideramos relevante a pesquisa com o manual didático Português contemporâneo: diálogo, reflexão e uso pela possibilidade de realizarmos uma análise deste objeto, em uma relação direta com teóricos com os quais dialogamos durante todo o processo investigativo. Vale também registrar a importância da temática aqui apresentada/discutida para o processo de formação do profissional em Letras e áreas afins, através de reflexões sobre os processos de Educação literária provocadas ao longo deste texto.

\section{Referências}

CASSIANO, Célia Cristina de Figueiredo. O mercado do livro didático no Brasil do século XXI - A entrada do capital espanhol na educação nacional. 1. ed. São Paulo: Unesp Editora, 2013. 
O ROMANTISMO BRASILEIRO EM FOCO: ANÁLISE DAS REPRESENTAÇÕES DE EDUCAÇÃO...

CHARTIER, Roger. A história cultural: entre práticas e representações. Rio de Janeiro: Difel, 1988.

CORACINI, Maria José (Org.). Interpretação, autoria e legitimação do livro didático. Campinas, SP: Pontes, 1999.

COSSON, Rildo. Letramento literário - teoria e prática. 1. ed. 3. reimp. São Paulo: Contexto, 2009.

JURADO, Shirley; ROJO, Roxane Helena Rodrigues. A leitura no ensino médio: o que dizem os documentos oficiais e o que se faz? In: BUZEN, Clecio; MENDONÇA, Márcia (Org.) Português no ensino médio e formação do professor. São Paulo: Parábola editora, 2006.

LEAHY-DIOS, Cyana. Educação literária como metáfora social: desvios e rumos. São Paulo: Martins Fontes, 2004.

SOARES, Magda. A escolarização da literatura infantil e juvenil. In: EVANGELISTA, Aracy Alves Martins et. all. A escolarização da leitura literária. 2. ed. 2. reimp. Belo Horizonte, MG: Autêntica, 2006.

\section{Manual didático consultado}

CEREJA, William Roberto; VIANA, Carolina Dias; CODENHOTO, Christiane Damien. Português contemporâneo: diálogo, reflexão e uso. v. 2. 1. ed. São Paulo: Saraiva, 2016.

\section{Sobre os autores}

Jaine Neves Pires: Graduada em Letras Vernáculas pela UNEB (2019, Campus XX -Brumado BA); Bolsista de Iniciação científica (2018-2019), Bolsista do Comitê local do PROLER (20162017), Integrante do grupo de pesquisa LEALLL - Linguagens e Educação: Alfabetização, Leitura, Linguística e Literatura. Atuou como professora de Língua Portuguesa no Colégio Estadual de Brumado (BA), em 2019.

Lattes: http://lattes.cnpq.br/8057060354276524.

E-mail: jainenevespires@gmail.com.

Oton Magno Santana dos Santos: Doutor em Educação pela UNICAMP (2017), Mestre em Letras: Linguagens e Representações (UESC - 2010), Professor Adjunto do curso de Letras da UNEB (Campus XX - Brumado), professor-pesquisador do Programa de Pós-Graduação em Estudo de Linguagens (PPGEL) da UNEB, Campus I (Salvador), Líder do grupo de Pesquisa LEALLL - Linguagens e Educação: Alfabetização, Leitura, Linguística e Literatura (UNEBDiretório Nacional/CNPq).

Lattes: http://lattes.cnpq.br/1727487434803907.

E-mail: otonmagno@gmail.com. 